\title{
Effect of rare-earth on the structural and magnetic properties of doped nickel ferrite
}

\author{
Rubiya Samad*, Basharat Want and Mehraj-ud-din-Rather \\ SSRL, Department of Physics, University of Kashmir, Hazratbal Srinagar-190006 \\ *Email: rubiyasamad007@gmail.com
}

Spinel ferrites due to magnetic properties are one of the most fascinating groups of the matters. Nickel ferrite has inverse spinel structure with extra ordinary applications in gas sensing, catalysts, drug delivery, magnetic adsorbent, micro- wave devices, etc. [1]. In Spinel ferrites, the choice of rare-earth ions allows a relative tenability of the magnetic properties such as magnetization or anisotropy, Curie temperature etc. [2].

Present work is focused on the investigation of structural and magnetic properties of rare-earth doped nickel ferrite. The nano-crystalline samples of pure and doped $\mathrm{NiFe}_{2} \mathrm{O}_{4}$ were prepared by glycine nitrate auto combustion route. The structural and magnetic properties were investigated using versatile techniques such as X-ray diffraction (XRD) and vibrating sample magnetometer. XRD confirms the cubic structure with Fd-3m space group. Magnetic hysteresis loops recorded at room temperature for all samples is shown in Figure 1. Magnetic parameters are given in table 1. From the Table 1 , it is clear that saturation magnetization increases with $\mathrm{Co}^{2+}$ and then decreases with increase in rare-earth ions.

Table 1: Magnetic parameters for $\mathrm{Ni}_{1-\mathrm{x}} \mathrm{Co}_{\mathrm{x}} \mathrm{R}_{\mathrm{y}} \mathrm{Fe}_{2-\mathrm{y}} \mathrm{O}_{4}$

\begin{tabular}{|l|l|l|l|l|}
\hline Sample & $\begin{array}{l}\mathrm{M}_{\mathrm{s}} \\
(\mathrm{emu} / \mathrm{g})\end{array}$ & $\begin{array}{l}\mathrm{M}_{\mathrm{r}} \\
(\mathrm{emu} / \mathrm{g})\end{array}$ & $\begin{array}{l}\mathrm{H}_{\mathrm{c}} \\
(\mathrm{Oe})\end{array}$ & $\mathrm{S}$ \\
\hline $\mathrm{X}=0.0, \mathrm{y}=0.0$ & 42.47 & 10.603 & 83.63 & 0.25 \\
\hline $\mathrm{X}=0.1, \mathrm{y}=0.0$ & 43.65 & 14.02 & 178.126 & 0.32 \\
\hline $\mathrm{X}=0.1, \mathrm{y}=0.05$ & 42.79 & 20.006 & 268.76 & 0.46 \\
\hline $\mathrm{X}=0.1, \mathrm{y}=0.1$ & 38.38 & 17.9 & 307.328 & 0.47 \\
\hline
\end{tabular}

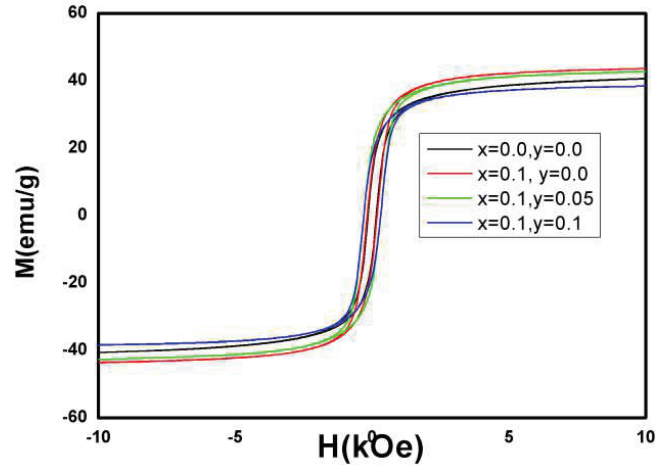

Figure 1: Magnetic hysteresis loop of $\mathrm{Ni}_{1-\mathrm{x}} \mathrm{Co}_{\mathrm{x}} \mathrm{R}_{\mathrm{y}} \mathrm{Fe}_{2-}$ ${ }_{\mathrm{y}} \mathrm{O}_{4}$

\section{References}

1. D. Carta, M. F. Casula, et.al J. Phys. Chem. C (2009), 113, 8606-8615.

2. R. Hochschild and H. Fuess, J. Mater. Chem., (2000), 10, 539-542. 